\title{
Study on Standard Time of Garment Sewing Based on GSD
}

\author{
Lihui Ren \\ Guangdong Vocational and Technical College Foshan Guangdong, 528041, China
}

Keywords: GSD, Standard time, Standard motion, GSD database.

\begin{abstract}
With the constant development and application of computer technology and advanced manufacturing technology, scientific and digital management has been generally accepted in clothing industry. Advantages of GSD in time normalization, method consistency and data controllability can effectively help clothing enterprises to reduce costs and improve production efficiency.
\end{abstract}

\section{Introduction}

GSD (General Sewing Data) is an engineering technology of method analysis and time study designed specially for clothing industry. GSD derives from MTM (Methods Time Measurement) database which is a predetermined motion time system. Standard time of corresponding motions can be found in the database. GSD analyzes all motions that can occur in the sewing process of sewing personnel according to the operation process of sewing industry and then forms operation standard time.

\section{GSD database}

GSD divides the operation in sewing industry into processing operation and machinery operation expressed with motion code as shown in table 1.

Table 1.

\begin{tabular}{|c|c|c|c|c|c|c|c|}
\hline \multicolumn{7}{|c|}{ Processing operation } & \multirow{2}{*}{$\begin{array}{l}\text { Machinery } \\
\text { operation }\end{array}$} \\
\hline \multicolumn{6}{|c|}{ Stage I } & Stage II & \\
\hline $\begin{array}{c}\text { Get or } \\
\text { match parts }\end{array}$ & $\begin{array}{c}\text { Align or } \\
\text { adjust parts }\end{array}$ & $\begin{array}{l}\text { Fold into a } \\
\text { shape }\end{array}$ & $\begin{array}{l}\text { Clip and } \\
\text { use tools }\end{array}$ & $\begin{array}{l}\text { Put } \\
\text { aside }\end{array}$ & $\begin{array}{l}\text { Operate the } \\
\text { machine }\end{array}$ & $\begin{array}{l}\text { Get and } \\
\text { put }\end{array}$ & Sewing \\
\hline $\mathrm{M}$ & A & $\mathrm{F}$ & $\mathrm{T}$ & A & $\mathrm{M}$ & $\mathrm{G}$ or $\mathrm{P}$ & $\mathrm{S}$ \\
\hline
\end{tabular}

Stage I of processing operation represents the category of basic motions in clothing industry. Basic motions in stage I can be described with therbligs of " $G$ " or "P” in stage II.

Standard time of processing operation.

Processing operation has 52 basic motions. Let's take "get and match parts" for example. It includes six basic motions such as "match and get two parts at the same time" or "match and get two parts respectively”.

Analysis on therbligs of "match and get two parts at the same time" is conducted, which finds that the motion is composed of 5 therbligs, i.e. "get-get-put-get-get". It can be expressed with motion code "GGPGG", as shown in fig.1. 


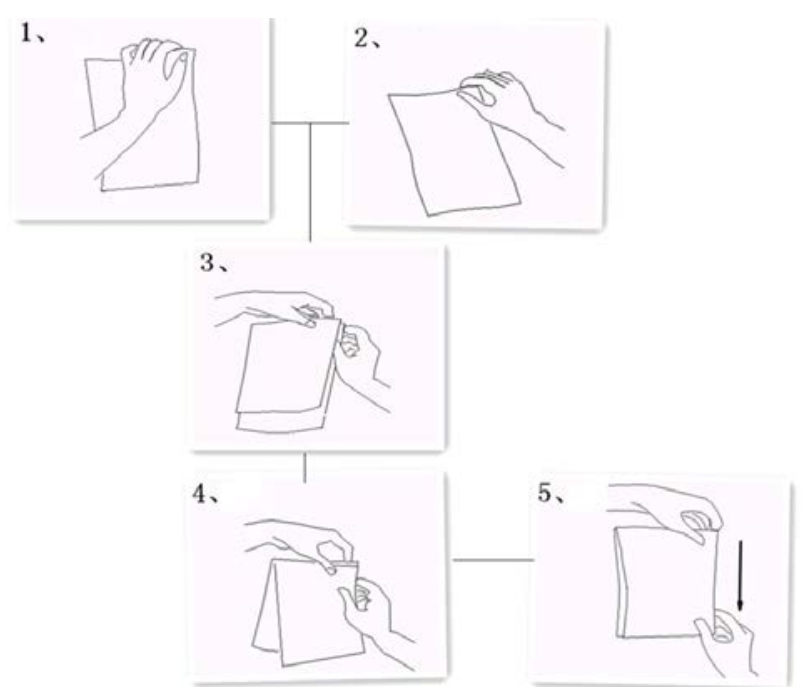

Fig.1

In motions above, left and right hands complete the first and second "get" at the same time. After garment pieces are put together, the left hand sorts one end of garment piece and the right hand slides down and sorts the other end, thus completing the whole set of motions. The operation time of corresponding therbligs is inquired in MTM database. It is obtained that standard time is 76TMU (TMU is the smallest unit of time. One second is 33.33TMU).

Table 2 can be obtained through analysis on six basic motions in "get and match parts" according to the process above.

Table 2.

\begin{tabular}{cccc}
\hline Name & \multicolumn{1}{c}{ Basic motion } & Therbligs & Standard time \\
\hline Get and match parts & Match and get two parts at the same time & G.G.P.G.G & 76 \\
\cline { 2 - 4 } & Match and get two parts respectively & G.P.G.P.G.G & 107 \\
\cline { 2 - 4 } & Match parts and press foot (not get) & P.G & 38 \\
\cline { 2 - 4 } & Match and add parts with single hand (easy) & G.P.G & 50 \\
\cline { 2 - 4 } & Match and add parts with single hand & G.P.G & 56 \\
\cline { 2 - 4 } & Match and add parts with both hands & G.P.G.P.G & 69 \\
\hline
\end{tabular}

Similarly, therbligs and corresponding standard time in 52 basic motions can be found. Standard time database of processing operation can be established.

\section{Standard time of machinery operation.}

Different factors such as machine used, sewing stitch and sewing length will produce influence on standard time of machinery operation. The code of standard time of machinery operation is composed of four parts, as shown in table 3.

Table 3.

\begin{tabular}{cccc}
\hline Sewing code & Primary sewing length $(\mathrm{cm})$ & \multicolumn{2}{c}{ Technical requirements } \\
\cline { 3 - 4 } & & Stitch requirements & Discontinuation accuracy \\
\hline S & 20 & $\mathrm{~N}$ & $\mathrm{~A}$ \\
\hline
\end{tabular}

Primary sewing length can be adjusted correspondingly according to actual sewing length. If sewing length is $40 \mathrm{~cm}$, the code is 40 .

Sewing requirements have four codes respectively representing different stitches. Different addition coefficients are given respectively according to different degree of difficulty, as shown in table 4.

Table 4.

\begin{tabular}{clcc}
\hline Code & \multicolumn{1}{c}{ Stitch } & Degree of difficulty & Addition rate \\
\hline $\mathrm{N}$ & Single-layer straight line & None & $0 \%$ \\
\hline L & A straight blind stitch & Low & $10 \%$ \\
\hline M & A straight open line or curved blind stitch & Middle & $20 \%$ \\
\hline H & A curved open line or within limited scope & High & $40 \%$ \\
\hline
\end{tabular}


Discontinuation accuracy will influence sewing speed. The higher the requirement for discontinuation accuracy is, the more the time spent will be, as shown in table 5 .

Table 5.

\begin{tabular}{cclc}
\hline Code & Discontinuation accuracy & \multicolumn{1}{c}{ Descriptions } & Time added (TMU) \\
\hline A & More than 1cm & Stop beside stitch or sewing till completion & 0 \\
\hline B & Within $1 \mathrm{~cm}$ & Stop for back stitching of blind stitch & 9 \\
\hline C & Within $0.5 \mathrm{~cm}$ & Stop for direction change or back stitching of open line & 20 \\
\hline
\end{tabular}

Calculation steps of sewing time are shown as below:

(1) Minimum sewing time

$$
\mathrm{MST}=\frac{S T \div \mathrm{CM}}{R P M \times 0.0006 \mathrm{~min}}
$$

ST refers to number of threads; CM refers to sewing length; RPM refers to maximum sewing speed of sewing machine, i.e. rotation number of wheel per minute when feet press the pedal. Rotation number per minute and number of threads per minute are the same because the needle moves up or down for each circle of rotation of motor, i.e. sewing completes one stitch.

(2) Calculation of feed speed

$$
\text { Feed speed }=\mathrm{RPM} /(\mathrm{ST} / \mathrm{CM})=\mathrm{CM} / \mathrm{min}
$$

The higher the feed speed is, the more the times of distributing control by sewing worker will be. Therefore, sewing time will also increase correspondingly. If feed speed is more than $445 \mathrm{CM} / \mathrm{min}$, high-speed coefficient HSF should be calculated; if it is less than the minimum value, HSF=fixed value 1.

(3) Calculation of high-speed coefficient

$$
\mathrm{HSF}=(4.5-\mathrm{MST}) 2 / 100+1
$$

(4) Calculation of sewing time

$$
\mathrm{T}=(\mathrm{MST} \times \mathrm{HSF} \times \mathrm{GT} \times \mathrm{CM})+17+\mathrm{P}
$$

Where, T refers to total processing time, GT refers to sewing type (N, L, M, H) of different degrees of difficulty and P refers to discontinuation accuracy (A, B, C).17 is fixed value, i.e. time spent for starting and stopping the machine.

The sequence of all operations of each employee per day can be described accurately through motion codes above, thus helping enterprises to establish a standard operating method. Meanwhile, accurate operation time can be provided.

\section{Steps for determining standard time of sewing}

Standard time of garment sewing is composed of GSD pure processing time and allowance time. Its factors of influence include processing flow, technology, equipment, worker, environment and standard motion.

\section{GSD pure processing time.}

Step 1: analyze garment style, specify technological requirements and determine the specification of raw and auxiliary materials, standard and required equipment.

Step 2: analyze garment process, divide minimum operating unit and make process flow chart.

Step 3: conduct motion analysis on minimum operating unit.

Conduct motion analysis on minimum operating unit with observation method or image analysis method, pick out appropriate motion code from GSD database, find out the corresponding working time and obtain GSD pure processing time. Let's take "stitch watch pocket mouth and stitch the sole to the upper of watch pocket" of jeans for example. Through therblig analysis, it can be decomposed into the following:

(1) Hold watch pocket with single hand (once); (2) Adjust and seize stitching position (twice); (3) Get (once); (4) Move cut-parts below presser foot (once); (5) Sew a 8cm straight open line and discontinue accurately (once); (6) Break stitches (once); (7) Put watch pocket with single hand (once); 
(8) Stick watch pocket (once); (9) Get watch pocket and pocket facing with both hands at the same time (watch pocket on the left hand) (once); (10) Fold end stitching with a finger (once); (11) Align at powder position (once); (12) Press and hold (once); (13) Move garment piece below presser foot (once); (14) Back stitching with computer (once); (15) Sew a 9cm multi-layer straight open line and discontinue accurately (once); (16) Turn the direction of garment piece (once); (17) Set down presser foot (once); (18) Fold end stitching with a finger (once); (19) Sew a 6cm multi-layer straight open line and discontinue accurately (once); (20) Turn the direction of garment piece (once); (21) Set down presser foot (once); (22) Align at powder position (once); (23) Sew a 9cm multi-layer straight open line and discontinue accurately (once); (24) Back stitching with computer (once); (25) Put back watch pocket with single hand (once)

The time of 25 therbligs is added together. GSD pure processing time of "stitch watch pocket mouth and stitch the sole to the upper of watch pocket" is 22.7s.In GSD data measurement, two principles should be stuck to: first, principle of motion economy, e.g. simultaneous operation of left and right hands; second, concept of continuous improvement.

However, pure processing time calculated with such method is not necessarily appropriate for all enterprises. In the process of actual application, processing time will be adjusted slightly under external influencing factors.

(1) Degree of worker training. Motions of workers during operation should be standardized. Workers without motion standardization will have some unconscious motions and increase processing time.(2) Preparation of machinery equipment. On the one hand, technical level of machine will influence processing time. On the other hand, it is necessary to readjust the machine before starting work so as to avoid the increase of processing time caused by machine fault.(3) Setting position of garment piece. The time for workers getting garment piece and putting it after completion will be influenced by the distance and level of placement of garment piece.

\section{Allowance time.}

Allowance time refers to additional time considering the influence of external factors on work such as machine downtime for adjustment, physiological needs of people and variety change when employees work all day. Generally, allowance time is directly added to GSD processing time in percentage form, which then becomes standard operating time.

Allowance time generally has five types: personal allowance, fatigue allowance, procedural allowance, special allowance and policy allowance.

(1) Personal allowance erefers to the time required for maintaining employees' comfort in work and psychological need, such as the time for drinking water and going to the bathroom.

(2) Fatigue allowance refers to the allowance due to the reduction of production efficiency caused by physical or psychological fatigue because of continuous work. Fatigue can be reduced but cannot be avoided completely through the improvement of operational method, the introduction of advanced equipment or the creation of good working environment.

(3) Procedural allowance refers to the allowance time required for inevitable delay in operation, such as the time of waiting in the case of machine fault or the time wasted for waiting for the previous process in production line. Procedural allowance time can be reduced through comprehensive equipment management or production line balance management.

(4) Special allowance refers to allowance permitted specially caused by process difficulty or fabric etc.

(5) Policy allowance belongs to allowance time given by management policy, i.e. extra allowance given to retain some special people or during the period of reform and transition of a company, e.g. compensatory allowance for retaining some old experienced and skillful employees in many domestic old-brand clothing enterprises. However, such allowance is often cancelled with the change of environment.

\section{Function of GSD standard time}

Garment sewing production belongs to semi-hand semi-mechanized work. The establishment of standard time is good for standardizing enterprise management work, reducing production cost and 
improving production efficiency.

Determine standard operation and establish more economical operating method.

The study on GSD standard time starts from therbligs in the operation of employees and helps administrators discover redundant and wasted motion in operation. Meanwhile, in the study on tiny motions, it is feasible to establish more economical operating method and improve operating standard with methods such as tool improvement for difficult operations in time.

Good for the balance of production line.

Reasonable allocation of resources such as machinery equipment and personnel according to standard time of each process can avoid waste caused by uneven resources and meanwhile make production line achieve the highest efficiency.

\section{As the basis of production plan.}

The basis of production plan is production capacity. Accurate standard time of production calculated can allow to obtain the information about daily, weekly and monthly production capacity of each production line more accurately and establish production plan more reasonably and scientifically under control.

Accurate and rapid budgeting of processing cost.

The essence of piece wage is hourly wage. As long as the processing cost of unit time is known, processing charges of clothing can be budgeted accurately and rapidly so as to provide theoretical basis for product offer and sales.

Provide basis for performance assessment of employees.

The comparison of target yield and actual yield is used as the standard for assessing the performance of employees.

\section{Application and promotion of GSD standard time in clothing enterprises}

The promotion of GSD standard time in clothing enterprises can be divided into four stages, as shown in fig.2.

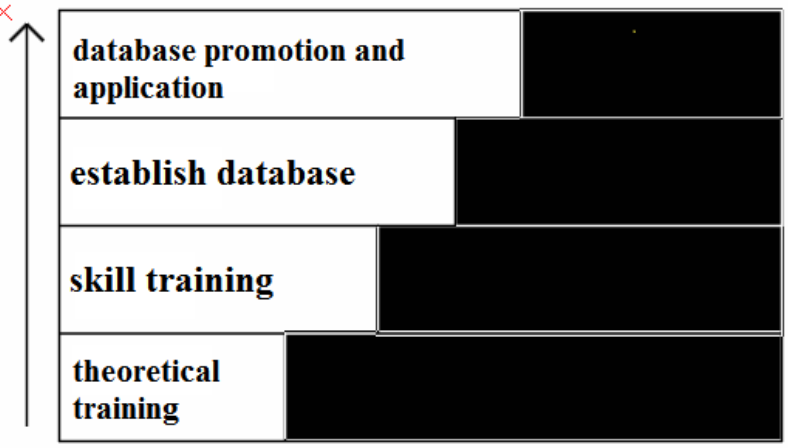

Fig.2

Stage I: theoretical training. Select employees with foundation and learning ability from enterprise for the training of GSD basic knowledge.

Stage II: skill training. Training contents include the analysis on garment style, garment production process, standard for time selection for employee test and measurement of GSD time requirements etc.

Stage III: establish database. GSD database appropriate for the enterprise should be established according to product features and management level of each enterprise.

Stage IV: database promotion and application. New styles received by enterprise should be analyzed and relevant data should be obtained from database. Data unavailable in database can be supplemented, thus improving enterprise database constantly.

Technologies of GSD in establishing time standard and improving operating method are not only limited to garment sewing operation. They can also be used in links such as cutting, pressing, inspection and packaging. Further study in the future is required. 


\section{References}

[1] Fu Wuxiong (Taiwan). Establishment of Standard Working Hour and Operation Improvement. Xiamen University Press, 2012.03:201-202

[2] Zhao Ran. Study on Establishment of Standard Working Hour in Clothing Production and Optimization of Production Line. Master's Thesis in Donghua University, 2012.12

[3] Wu Shigang, Mu Hong. Method for Establishing Norm of Working Hour for Typical Process of Clothing, Journal of Textile Research, 2011,32(6):151-154

[4] Han Shaojie. Study on Balance of Production Line Operation of Western-style Clothes and Digital Management. Academic Dissertation of Master Degree Candidate in Donghua University, 2010. 